\title{
O IDEB e a construção de um modelo de accountability na educação básica brasileira
}

\author{
Marilda Pasqual Schneideri \& Elton Luiz Nardii \\ Universidade do Oeste de Santa Catarina, Brasil
}

\begin{abstract}
Resumo
O objetivo deste estudo é analisar o Índice de Desenvolvimento da Educação Básica (IDEB), enquanto uma medida do governo brasileiro para aferir o desempenho educacional dos estudantes. A análise toma como referência o conceito de accountability, tal como proposto por alguns autores, e procura verificar quais variáveis das que integram um sistema completo estão mais presentes na política encampada pela via do IDEB, como elas se relacionam e em que medida o índice, criado em 2007 para aferir a qualidade da educação básica brasileira, permite avançar em relação às concepções predominantes de accountability, nomeadamente as que integram avaliações externas, prestação de contas e responsabilização como elementos de uma política educacional de qualidade. Com base no tensionamento entre as variáveis que compõem um sistema abrangente e complexo, assinala potencialidades do IDEB considerando condições de superação de visões reducionistas e conservadoras de accountability educacional.
\end{abstract}

Palavras-chave

IDEB; Accountability educacional; Educação básica brasileira; Qualidade da educação

\section{Introdução}

O Brasil é um país federativo, formado pela União, estados, Distrito Federal e municípios. Pautadas na descentralização e na autonomia político- 
administrativa, as relações intergovernamentais em que estão envolvidos os entes federados devem ser orientadas pela cooperação com vistas ao desenvolvimento e bem-estar em âmbito nacional.

Não obstante essa forma descentralizada de governo, o país vem perpetrando, desde a década de 1990 e na esteira de reformas de corte neoliberal, medidas de impacto no campo educacional, muitas das quais implicam a própria atuação dos governos subnacionais e o seu papel na implementação e administração da oferta da educação básica pública. Não raro, vozes contrárias a diversas medidas referem um quadro de ingerências e, no limite, de desrespeito ao pacto federativo.

Como peça substancial do conjunto de ações em curso, foi criado, em 2007, pelo Ministério da Educação, o IDEB (Índice de Desenvolvimento da Educação Básica). Aportado em um programa de governo denominado Plano de Desenvolvimento da Educação (PDE), o IDEB foi apresentado à nação como uma ferramenta inovadora de aferição de resultados educacionais de estados, municípios, redes de ensino e escolas, pretensamente com vistas à melhoria da qualidade na educação básica brasileira. Por possibilitar acompanhamento de metas educacionais por escola, representa um mecanismo de monitoramento do ensino ofertado no país, em um contexto no qual toda a sociedade brasileira é conclamada oficialmente a assumir compromisso com a melhoria da qualidade da educação ${ }^{1}$.

A meta final do IDEB tem seu alcance nacional estimado para 2021, com divulgação do resultado em 2022, ano do bicentenário da Independência do Brasil. Significa dizer que, em 2021, o Brasil deve atingir, considerando os anos iniciais do ensino fundamental ( $1^{\mathrm{a}}$ a $5^{\mathrm{a}}$ séries), IDEB 6,0 (seis), nível médio de qualidade obtido em 2003 pelos países desenvolvidos que participam do PISA (Programme for International Student Assessment) ${ }^{2}$. No caso dos anos finais ( $6^{\mathrm{a}}$ a $9^{\mathrm{a}}$ séries), estima-se que, em termos nacionais, a meta 6,0 será alcançada no ano de 2025 e, no ensino médio, a expectativa é que essa meta seja obtida somente em 2028.

Porquanto o IDEB possua a avaliação externa como elemento basilar e figure como peça mobilizadora de toda a comunidade educacional pelo alcance de metas educacionais oficiais, vem sendo apontado como peça importante de uma política nacional de accountability da educação brasileira (Fernandes \& Gremaud, 2009). Para Fernandes e Gremaud (2009), a 
incorporação de objetivos de accountability na educação básica representa uma das três principais inovações introduzidas pelo PDE. As outras duas inovações teriam sido: (i) "a criação de um indicador sintético da qualidade da educação básica, que considera tanto o desempenho dos estudantes em exames padronizados quanto a progressão desses alunos no sistema"; e (ii) "a definição de metas tanto para o país quanto para cada sistema e escola em particular" (p. 1).

Nas quatro aferições ${ }^{3}$ realizadas desde que iniciou a série histórica do IDEB $^{4}$, importantes avanços foram demonstrados por escolas, redes e sistemas de ensino brasileiros nas três etapas da educação básica (anos iniciais, anos finais e ensino médio). É bem verdade que, enquanto nos anos iniciais o desempenho das escolas evidencia superação das metas bienais, no ensino médio foram registradas, até agora, as pontuações mais baixas das três etapas da educação básica.

Comparados os resultados entre estados e municípios são evidenciadas também realidades díspares. Enquanto alguns deles deverão alcançar as metas previstas, ou até ultrapassá-las, antes mesmo do prazo estipulado, outros terão dificuldade para cumprir as metas intermediárias, o que certamente impactará o alcance da meta final $(6,0)$, em 2021. De todo modo, importa salientar que o Brasil está avançando nas metas educacionais do IDEB, confirmando o esforço de escolas, redes e municípios no alcance das projeções traçadas pelo governo federal para cada biênio.

Referido esse panorama, o estudo propõe analisar o IDEB no contexto das políticas de accountability, enquanto uma iniciativa do governo brasileiro para elevar o desempenho educacional dos estudantes. Interessa, mais precisamente, identificar quais variáveis das que, segundo alguns autores, integram um sistema de accountability estão mais presentes no mecanismo do IDEB e no seu contexto de ação e como elas se relacionam. Interessa, ainda, verificar se, com a criação desse índice, é possível avançar em relação a concepções mais estreitas de accountability, nomeadamente as que utilizam avaliações externas como um de seus elementos centrais.

Dada a complexidade da tarefa, o texto inicia tratando do conceito de accountability e avança evidenciando seus desdobramentos no campo educacional. Em relação ao primeiro aspecto, utiliza como referencial teórico principalmente estudos de Pollitt (1993, 2003), Schedler (2004) e Erkkilä 
(2007). O estudo das formas de accountability no campo educacional está ancorado na sociologia da avaliação, com aporte especialmente nas reflexões de Afonso (2009a; 2009b; 2010; 2012).

Tecido o quadro teórico, o texto segue efetuando uma análise do IDEB, tendo à frente as variáveis que, segundo Afonso (2009a; 2009b; 2010), informam a constituição de um sistema amplo de accountability educacional: avaliação, prestação de contas e responsabilização. Por fim, com base no tensionamento entre essas variáveis, e de como elas se corporificam no IDEB, o texto busca realçar elementos que remetem a uma visão reducionista e conservadora de accountability no campo da educação, assim como apontar alguns elementos para sua superação.

\section{Accountability e accountability educacional}

Apesar de sua existência secular, o termo accountability permanece sem uma tradução única, podendo, segundo Bovens (2007), "significar coisas diferentes para pessoas diferentes". A tradução mais usual tem sido prestação de contas ou responsabilização, mas sua concepção atual não se esgota nesses dois vocábulos. Por se tratar de um tema em expansão (Mulgan, 2000), a accountability vem sendo discutida a partir de uma variedade de abordagens e perspectivas, muitas delas nem sempre convergentes, porém comumente associadas a um discurso político-ideológico e orientadas por reformas na administração pública dos países, nomeadamente as efetuadas a partir dos anos de 1970 .

Para Pollitt (1993), as reformas na administração pública, ocorridas no século $X X$, focalizaram a eficiência e a eficácia, em favor das quais teria sido introduzida a descentralização dos serviços. Consoante destaca o autor, essas reformas pautaram-se, inicialmente, no modelo administrativo gerencial, com a lógica de mercado sendo transposta para a gestão pública. Com o passar do tempo, consequências indesejadas do modelo gerencial puro, notadamente apontadas no debate inglês, ter-lhe-iam rendido transformações que trouxeram, segundo esse autor, abordagens alternativas como o Consumerism e o Public Service Orientation (PSO).

O Consumerism ou "satisfação do consumidor" adotou a perspectiva da qualidade como estratégia para essa satisfação. As medidas encetadas 
buscavam tornar o poder público mais ágil e competitivo, para o que cabia, entre outras estratégias, operar a descentralização administrativa (para aproximar o centro de decisões aos consumidores) e mobilizar a competição entre organizações públicas. Abrucio (1997) adverte que, embora tenha avançado significativamente em relação ao modelo original, várias críticas foram dirigidas a essa abordagem, notadamente na relação entre o governo prestador de serviços públicos e a população. Conforme destaca, "a crítica mais geral é direcionada ao conceito de consumidor de serviços públicos" ( $p$. 24).

Em outra direção, mas não contrário ao Consumerim, segundo Pollitt (1993) o PSO marca um avanço em relação aos modelos neotayloristas de gestão 5 porquanto, "além de ter como foco o cidadão, também reconhece a necessidade de os serviços públicos serem orientados por valores voltados à escolha coletiva, de domínio público" (p. 149). Consoante o autor, no contexto da Nova Gestão Pública o PSO representa "uma alternativa mais atual à ideologia gerencial" (p. 149), em boa medida porque a forma gerencial pura estaria em processo de progressivo desgaste.

Conforme explica Pollitt (1993), desenvolvido inicialmente para impulsionar a administração local do Reino Unido, extremamente prejudicada com a limitação de recursos e a hostilização do governo central, bem como para motivar funcionários no redirecionamento de suas atividades, o PSO teria sido posteriormente "ampliado para uma abordagem da gestão no domínio público em geral" (p. 149). Na nova perspectiva proposta, o público, em sua acepção mais estreita, deve ser visto como parceiro e não como cliente. É por conta dessa compreensão que questões como participação e responsabilização teriam passado a ser fortemente defendidas por seus adeptos. Pollitt (1993) argumenta que a característica-chave do PSO é "a accountability pública" (p. 149). Para o autor, essa perspectiva vai além da ideia de prestação de contas, requerendo, por parte do gestor público, capacidade para encontrar formas diferentes e níveis também diferentes de "dar resposta ao público" (p. 151). Sustenta-se, portanto, em valores coletivos de gestão, o que, segundo esse autor, demarca o avanço em relação ao Consumerism transplantado do setor privado.

As características do novo modelo incluem: tomar o domínio público como um lugar para aprendizagem social; considerar o conceito de estratégia 
não como se referindo a uma postura competitiva das organizações (como no modelo do setor privado), mas a um conjunto de propósitos que se refletem como "aspirações públicas reveladas por um processo de debate público" (Pollitt, 1993, p. 150); tomar o orçamento como um exercício de escolha determinada através da negociação política; basear o racionamento dos serviços públicos em uma avaliação de necessidade e efetuado de forma a explicitar os propósitos do racionamento; entre outras.

Apesar dos avanços apontados pelo autor em relação à abordagem anterior, temas como eficiência, qualidade, avaliação de desempenho, flexibilidade gerencial, planejamento estratégico, ainda que tratados sob o ponto de vista da esfera pública, continuam a encontrar abrigo no PSO. O que ocorre, no entanto, é uma alteração de abordagem. Ao invés de uma mudança individual no mercado, propõe uma mudança coletiva na política; no lugar de uma gestão baseada na demanda e no preço, uma que considere a necessidade e equidade de recursos; em vez da satisfação do mercado, a procura pela justiça; no lugar da soberania do cliente, a da cidadania; no lugar da competição como instrumento de mercado, a ação coletiva como instrumento de política; por fim, no lugar da "saída" como estímulo, "a voz como condição" (Pollitt, 1993, p. 155).

Atento a essas alternativas, Erkkilä (2007) reforça que as mudanças estruturais que ocorreram na política e administração pública, em vários países, desde o final dos anos de 1980, podem estar convergindo "para uma alteração na conceituação original de accountability" (p. 2). Consoante o autor, seriam os conceitos de governança e governação que teriam mudado, trazendo demandas por alterações na percepção sobre como os mecanismos de accountability deveriam atuar. A suspeita de Erkkilä (2007) é que mudanças nas formas de governação estariam desafiando os sistemas tradicionais. Ou seja, à medida que mecanismos tradicionais são colocados em suspeição em um novo contexto administrativo, outros meios de controle seriam postos em movimento, afetando tanto o sentido de responsabilização como o da prestação de contas. Por isso, para o autor, maior atenção deveria ser dada às alterações nos seus mecanismos a partir das novas formas de governação em curso nos países. Corroborando essa visão, Pollitt (2003) advoga que a accountability desempenha um papel central no conjunto de ideias que compõem o modelo de democracia liberal e que mudanças 
recentes na maioria dos setores públicos têm provocado adequação de conceitos tradicionais, compelindo a "um debate internacional sobre a forma como os mecanismos tradicionais podem ser completados (não substituídos) por outras formas" (p. 98). Para o autor, dada a complexidade do tema, "não existe ainda um modelo único de accountability" (p. 98).

A despeito das alterações que o conceito de accountability vem sofrendo, e das diferentes leituras que oferece, a concepção matricial remete seu significado ao direito de alguém exigir prestação de contas e à obrigação ou dever, de quem é chamado a prestar contas, de fazê-lo (Mulgan, 2000; Pollitt, 2003; Schedler, 2004). Contempla, portanto, duas dimensões: a de obrigação - por parte de quem presta contas - e a de direito - por parte de quem solicita determinada informação. Para Schedler (2004), o direito de alguém solicitar e receber informações implica a obrigação correspondente de alguém disponibilizar informações.

Com lugar comum na literatura da administração pública e da ciência política, o uso de modelos e objetivos de accountability alastrou-se a partir dos anos de 1970, também para o campo educacional. Como parte do discurso político-ideológico que anuncia preocupação com a qualidade dos serviços públicos, tem sido privilegiada a associação entre a accountability educacional e os procedimentos de avaliação vincados em testes padronizados, com ampla divulgação dos resultados. Nesses casos, como ingrediente de um processo de responsabilização das escolas e professores, tem-se, comumente, o estabelecimento de padrões de desempenho e a aplicação de sanções ou recompensas.

Afonso (2009a; 2009b; 2010) vem insistindo na importância do pilar da avaliação na constituição de um modelo mais amplo e abrangente de accountability. Para o autor, um sistema completo de accountability educacional, que não se circunscreve nas razões de um pensamento único e neoconservador como os referidos aqui, inclui a prestação de contas, a responsabilização e a avaliação como partes integradas e integráveis de um projeto nacional de educação. $\mathrm{Na}$ falta de um desses pilares, teríamos formas parcelares de accountability, e não um modelo completo. Em um sistema mais amplo, como o que o autor propõe, enquanto a prestação de contas consubstancia o momento da justificação, da informação, da produção de argumentações e da elaboração e publicização de relatórios, o pilar da 
avaliação caracteriza o ex-ante e o ex-post deste processo. Ou seja, ele pode tanto anteceder a prestação de contas como ocorrer entre esta e a fase de responsabilização. Consoante Afonso (2010), quer numa ou noutra situação, a avaliação serve o propósito de "produzir juízo de valor sobre uma determinada realidade social" (p. 151), permitindo a recolha, o tratamento e a análise de informações. Sobre o pilar da responsabilização ${ }^{6}$, Afonso (2009a) adverte que sem garantia de processos credíveis, válidos e fidedignos de avaliação, os quais permitam emitir juízo de valor sobre práticas, instituições, contextos e políticas, "ficam prejudicadas as formas de prestação de contas e de responsabilização, ou seja, uma parte fundamental dos processos de accountability" (p. 15).

Em vários países, a accountability tornou-se parte de um discurso transversal, com consequências nas políticas educacionais. Com base nos argumentos da ineficácia dos métodos pedagógicos, do mau uso da autonomia profissional dos professores, do fortalecimento do Estado como mecanismo de controle e da racionalização dos investimentos públicos, comumente têm sido adotadas políticas de responsabilização e de prestação de contas sem necessária correspondência com práticas democráticas de avaliação da educação.

Em Afonso (2009b), porquanto um sistema de accountability implica uma "teia complexa de relações, interdependências e reciprocidades" ( $p$ 15) é que, não raras vezes, defrontamo-nos com práticas desvinculadas de processos credíveis de avaliação, comprometendo as possibilidades de superação de modelos vincados em pressupostos reducionistas. Na prática, muitas vezes os resultados dessas avaliações assumem o status de tradutores da qualidade, na medida em que a obtenção de índices desejáveis e previamente estabelecidos pressupõe melhoria educacional, sobretudo em nível de escola. Nesse nível em particular, não raro, a avaliação, enquanto categoria intrínseca ao processo de ensino-aprendizagem e ao projeto político-pedagógico da escola, é suplantada pela égide das avaliações centralizadas com as quais as escolas são levadas a concentrar esforços na produção de índices projetados externamente.

O Estado determina os princípios e as bases da avaliação, desenvolve os exames, aplica os testes, corrige-os, afere e divulga os resultados. A partir dos resultados obtidos, as redes e instituições de ensino são compelidas a 
prestar contas, criando estratégias e implementando ações com vistas a reverter números indesejáveis. Nesse contexto, as avaliações passam a constituir elemento primordial tanto para a tomada de decisões como para a responsabilização, desconsiderando-se na maioria das vezes os percursos individuais das escolas e as condições intra e extraescolares que afetam as possiblidades concretas de melhoria da qualidade educacional. Por outro lado, a imposição para a produção de números favoráveis, em vista de metas educacionais traçadas para cada escola e rede, tem levado instituições de ensino a construir estratégias capazes de alterar os resultados educacionais sem, no entanto, encetar mudanças significativas nos processos pedagógicos.

Por razões como as apresentadas, Afonso (2009a; 2009b; 2010) considera as avaliações padronizadas e externas, na forma como vêm sendo desenvolvidas atualmente em muitos países, como formas parcelares de accountability. Para o autor, nos moldes como vêm sendo realizadas, essas avaliações consubstanciam um modelo de responsabilização, alicerçado em apenas alguns elementos de accountability.

No caso do Brasil, as recentes mudanças processadas no âmbito da educação básica, especialmente a partir do lançamento do PDE, expandiram o papel das avaliações externas colocando-as no epicentro das políticas educacionais encampadas pelo MEC na última década. A criação do IDEB, como um índice que combina resultados de exames padronizados com dados de fluxo escolar, uniu à perspectiva de avaliação para o diagnóstico e monitoramento a noção de accountability.

\section{O IDEB e implantação de um sistema de accountability no Brasil}

Desde a publicização do PDE, em 2007, o Brasil adotou um "plano executivo" (MEC, 2007, p. 11), no qual metas, ações e programas governamentais são abrigados. As ações que o compõem estão colmatadas em seis pilares: visão sistêmica da educação; territorialidade; desenvolvimento; regime de colaboração; responsabilização; mobilização social. Como imperativos na consecução de seus propósitos, de melhoria da qualidade educacional, "a responsabilização (o que se conhece na literatura 
como accountability) e mobilização social" são consideradas, no documento, "dimensões indispensáveis de um plano de desenvolvimento da educação" (MEC, 2007, pp. 16-17).

A mobilização da sociedade brasileira é conclamada oficialmente pelo Decreto n. 6.094, de 24 de abril de 2007, que pretensamente adjudica o compromisso de todos pela educação e, em seu art. $1^{\circ}$, estabelece o Plano de Metas Compromisso Todos pela Educação. Segundo o Decreto, o Plano de Metas "é a conjugação dos esforços da União, Estados, Distrito Federal e Municípios, atuando em regime de colaboração, das famílias e da comunidade, em proveito da melhoria da qualidade da educação básica".

Como peça do PDE, o IDEB traduz a pretensão de dar conta da qualidade da educação básica brasileira. De acordo com Reynaldo Fernandes, presidente do Inep quando da criação do índice e também do PDE, "possuir um indicador de desenvolvimento educacional seria desejável, entre outros motivos, para: a) detectar escolas e/ou redes de ensino cujos alunos apresentem baixa performance e b) monitorar a evolução temporal do desempenho dos alunos dessas escolas elou redes de ensino" (Fernandes, 2007, p. 8).

Ainda que, em termos legais, e consoante anunciam os documentos a que nos referimos, a melhoria educacional implique conjugação de esforços de todos os entes federados, o que vimos observando é que a responsabilização pelos resultados educacionais recai, de forma indelével, sobre escolas e redes públicas de ensino. Isso porque os indicadores que conformam o índice são aferidos a partir de dados dos alunos de cada escola, cabendo a esta última, enquanto "espaço de produção desses dados", responder pelos resultados alcançados.

Pretensamente, o IDEB traduz o quanto as unidades escolares, os municípios e os estados avançaram em relação às suas metas e isso constitui importante referência à prestação de contas acerca das metas de qualidade defendidas pela via desse índice. Uma das principais polêmicas, no entanto, recai fundamentalmente na sua capacidade de tradução da qualidade. $O$ IDEB é constituído pelo produto de dois indicadores, sendo um deles fruto do resultado obtido pelos estudantes em avaliações externas, quer seja na Prova Brasil (para o IDEB das escolas, das redes e dos municípios) ou no Saeb (para a constituição do IDEB das unidades da federação, das regiões e do 
país, com um todo). A pontuação média dos estudantes nos exames constitui o indicador de desempenho $(\mathrm{N})$, indicado em valores entre zero e dez.

Foi a partir de 2005, com as mudanças realizadas no sistema de avaliação brasileiro, que o Saeb (Sistema de Avaliação da Educação Básica), criado em 1990, passou a ser composto por duas avaliações. Uma delas é a Prova Brasil, também designada de Anresc (Avaliação Nacional de Rendimento Escolar), e a outra a Aneb (Avaliação Nacional da Educação Básica), que manteve os objetivos e as características do Saeb na sua constituição matricial tendo, por essa razão, mantido a designação de Saeb nas publicações e demais materiais de divulgação e de aplicação do exame. Desde então, o Saeb caracteriza-se por ser uma avaliação bienal e amostral, de larga escala, externa aos sistemas de ensino, que fornece informações sobre a situação educacional brasileira de alunos de $5^{\mathrm{a}}$ e $9^{\mathrm{a}}$ séries do ensino fundamental e $3^{a}$ série do ensino médio, por regiões, redes de ensino pública e privada, e unidades da federação. As informações são coletadas a partir da realização de um exame de proficiência em Língua Portuguesa (leitura) e Matemática (resolução de problemas) e pelos dados de um questionário destinado a diretores e professores de todas as escolas, a cada edição do exame. Por sua vez, a Prova Brasil compreende uma avaliação também externa, realizada nas mesmas disciplinas do Saeb e com a mesma frequência (bianualmente). Porém, ao contrário do Saeb, ela tem abrangência censitária, ou seja, avalia o desempenho dos estudantes de $5^{\mathrm{a}}$ e $9^{\mathrm{a}}$ séries do ensino fundamental de todas as escolas públicas com pelo menos 20 alunos, situadas nas áreas rural e urbana do país.

Com a criação do IDEB, essas duas avaliações se fundiram, constituindo novamente uma única avaliação, de caráter nacional e abrangente, que utiliza os mesmos instrumentos - testes e questionários -, conhecida por Saeb. No entanto, como assinalado, os segmentos que constituem o Saeb, mas não a Prova Brasil, são amostrais, e os que constituem a Prova Brasil são censitários. Por sua abrangência censitária, alcance somente possível com as mudanças efetuadas em 2005, é creditado a essa avaliação maior potencial em termos do monitoramento de resultados educacionais. Porque fornece dados por escola, por rede e por município, é considerada a primeira avaliação externa com objetivos de accountability da educação básica 7 no Brasil. No entanto, para Fernandes e Gremaud (2009), 
trata-se de um indicador para uma "accountability fraca", especialmente porque "tanto a Prova Brasil quanto o Saeb são avaliações com adesão voluntária por parte das Secretarias de Educação" (p. 11). Segundo esses autores, seria somente a partir da ampla divulgação dos resultados dessas avaliações que o Brasil passou a contar com "um sistema de avaliação para diagnóstico e também com um programa de 'accountability fraca', por escolas e redes de ensino". (Fernandes \& Gremaud, 2009, p. 11)

O segundo indicador do IDEB é representado pelo rendimento escolar $(P)$, expresso por valores entre zero e um, relacionados às taxas de aprovação dos alunos na etapa de ensino. A informação correspondente a esse indicador é obtida por dados extraídos do Censo Escolar, informado anualmente pelas escolas. $O$ indicador de rendimento é o inverso do tempo médio em anos que os alunos de uma escola, rede de ensino, município, estado ou mesmo do país levam para completar uma série ${ }^{8}$, o que pode ser traduzido na seguinte equação: IDEB $=N \times(1 / T)$. Se o fluxo escolar for regular, ou seja, se o tempo médio de conclusão de cada série for de um ano, - IDEB equivalerá ao indicador de desempenho obtido a partir dos dados da Prova Brasil/Saeb. Do contrário, quanto maior a reprovação e o abandono registrados na etapa, maior será o tempo médio $(T)$ de conclusão de uma série, o que claramente penaliza o IDEB. Para Fernandes (2007), o índice é "explícito em relação à 'taxa de troca' entre probabilidade de aprovação e proficiência dos estudantes" (p. 8).

Em termos práticos, a criação desse índice permitiu que os resultados censitários da Prova Brasil adquirissem maior visibilidade no cenário educacional, induzindo gestores, professores e alunos a um olhar mais atento ao exame, quer seja no momento de sua aplicação ou a partir da divulgação de seus resultados. Ainda que sem conferir, até ao momento, premiações ou castigos explícitos em termos de política educacional, a divulgação em escala nacional produz efeito de responsabilização sobre escolas e redes públicas de ensino. Afora isso, destaca-se o fato de que, por meio de um plano designado PAR (Plano de Ações Articuladas) ${ }^{9}$, municípios considerados com baixa pontuação no IDEB (de acordo com critérios do MEC) são chamados a adotar medidas que elevem o seu índice de modo a superar a condição de prioritários.

Unindo a perspectiva de monitoramento do fluxo escolar e de desempenho de estudantes em avaliações externas em vista de um 
determinado padrão de qualidade educacional, o IDEB é considerado por Fernandes e Gremaud (2009) um instrumento com finalidades de accountability que supera o modelo instituído pela Prova Brasil porquanto permite "contornar os riscos de agravar os problemas de fluxo que um sistema de accountability tradicional poderia gerar em m país como o Brasil" (p. 14). Ao índice é creditada capacidade de congregar objetivos mais consistentes de accountability justamente por trabalhar com metas claras e concretas de qualidade, a serem atingidas por escola e por dependência administrativa (federal, estadual, municipal). Outra medida é que ele atua de modo a comprometer e responsabilizar governos estaduais, municipais e escolas pelos resultados. A construção de um ranking das escolas, por parte da mídia, assim como o oferecimento de assistência técnica e financeira, pelo MEC, para os municípios prioritários, são exemplos de iniciativas que corroboram a responsabilização e que, a nosso ver, reforçam a existência de uma política de accountability para a educação básica no Brasil.

Dos pilares que, de acordo com Afonso (2009a; 2009b; 2010), compõem um sistema (formal e complexo) de accountability (avaliação, prestação de contas e responsabilização), os que compreendem a avaliação e a prestação de contas são facilmente perceptíveis na composição do IDEB. Consoante destacado, o pilar da avaliação é representado pela incorporação dos resultados da Prova Brasil e Saeb e de rendimento representados pelas taxas de aprovação de cada etapa avaliada. Amplamente disseminados na literatura nacional e internacional, os exames que constituem avaliações em larga escala são predominantemente quantitativos, com objetivos previamente definidos e com métodos de mensuração estandardizados (Afonso, 2009a). Encerram-se, portanto, nos pressupostos do chamado Estado-Avaliador cuja vertente é o New Public Management. A dimensão estruturante do pilar da avaliação, nesse caso, é a recolha e baseada em exames externos.

Ainda que, na composição do IDEB, aos dados da avaliação externa se associem os do rendimento, o que poderia significar algum avanço em relação a modelos mais conservadores de accountability educacional, sobre essa combinação recaem ressalvas. Consoante apontado, dadas as possíveis dificuldades em lograr o êxito desejável nos exames, escolas e redes de ensino podem ser motivadas a atuar com baixas taxas de 
reprovação sem que seja assegurada a melhoria significativa na proficiência das crianças e jovens nas áreas alvo de aferição pela Prova Brasil. Por essa razão, parece adequado afirmar que, a despeito de possíveis avanços em relação às condições de monitoramento do desenvolvimento educacional das escolas, o IDEB se constitui por meio de um processo cujo objetivo maior é a prestação de contas, esta condicionada por uma avaliação ex-ante de caráter abrangente e concretizada, especialmente, pela ampla publicização do índice oficial alcançado pelas escolas.

Em um sistema (formal e complexo) de accountability, a prestação de contas possui duas dimensões estruturantes: uma de informação e outra de justificação. Para Afonso (2009b, p. 59), esse pilar compreende tanto o direito de alguém pedir informações (informar) como o de exigir justificações (justificar). Logo, permite uma ponte permanente de comunicação, devendo, por isso, orientar-se "pela transparência, atender ao direito à informação e ter em consideração outros princípios legais e éticos congruentes com as especificidades das situações (...)" (p. 59). Apesar de implicada em um sentido claro de obrigação e dever, em Schedler (2004), a noção de prestação de contas pressupõe uma relação de diálogo entre os atores que exigem e os que prestam contas, sendo, portanto, "oposta não somente ao exercício mudo do poder senão também ao controle mudo e unilateral do poder" (p. 13). Remete, pois, a uma atividade que, em primeira instância, é comunicativa, porquanto sustentada na argumentação (informação e justificação), na transparência das informações e na validade das razões, evocando, por isso, a ideia de diálogo crítico que, para o autor, implicaria "um jogo interativo, um ir e vir de perguntas e respostas, de argumentos e contra-argumentos" (Schedler, 2004, p. 14).

Numa concepção fundada em princípios teórico-metodológicos, políticos e axiológicos democráticos, como o Brasil defende desde a promulgação da Constituição Federal, em 1988, a prestação de contas pode constituir instrumento para a construção de diferentes graus de autonomia no quadro de políticas públicas fundadas em valores e princípios verdadeiramente democráticos. No entanto, a nosso ver, essa prestação deveria ser acompanhada de uma avaliação que, por ser precedente e/ou consequente, permitiria a recolha, o tratamento e a análise de informações acerca da realidade educacional. 
Associada à informação e justificação, há ainda a dimensão da imposição, que, em Afonso (2009a; 2009b), corresponde ao pilar da responsabilização. Inseparável desta e uma consequência possível da prestação de contas, a responsabilização implica ter de assumir as consequências (positivas e negativas) dos atos praticados. Assim, não obstante esse sentido, predominante, mas restritivo, se tomada a partir da ideia de um "trabalho colectivo, reflexivo e mais comprometido" (Afonso, 2009b, p. 59), a responsabilização pode evocar não somente a imposição de sanções negativas, mas ser interpretada também como tendo consequências positivas. Logo, pode referir-se à conquista de espaços de participação, os quais permitam reforçar os princípios de autonomia e cidadania ativa. Todavia, isto exige rupturas com concepções que não são fáceis de alterar. Talvez, por isso, quando os discursos não estiverem bem contextualizados ou fundamentados se deva falar mais de consequências e menos de responsabilização.

No caso em análise, as evidências aqui produzidas confluem para a inexistência de uma iniciativa deliberada, por parte das escolas e das redes de ensino, de divulgar resultados da Prova Brasil e dados de aprovação (indicadores do IDEB) e, tampouco, uma escolha decidida pela comunidade escolar sobre quais informações, das produzidas pela escola, seriam mais relevantes informar e publicizar como tradutoras da qualidade alcançada. Apesar de haver evidência de prestação de contas por parte das escolas, essa prestação não se dá a partir de uma avaliação auto-referenciada, com finalidade diagnóstica, como a que Afonso (2009a; 2009b; 2010) defende em um sistema amplo e complexo de accountability (quer seja ela ex-ante ou expost). Com os resultados dos exames divulgados por escola e por esfera administrativa, verifica-se um aumento na transparência dos resultados, conferindo à prestação de contas um elemento importante. De fato, há uma avaliação que precede a prestação de contas e, a partir da sua divulgação, as escolas são responsabilizadas pelos resultados. Porém, consoante assinalado, essa avaliação e a prestação de contas correspondente não asseguram amplo diálogo entre quem presta contas e quem as solicita. Prevalece uma relação unilateral entre as partes envolvidas, recaindo sobre a escola a obrigação de justificar os resultados alcançados à comunidade. 
O Estado procede à avaliação das escolas e sistemas de ensino de acordo com os critérios de composição do IDEB e informa os resultados à comunidade em geral por meio de mecanismos da mass media que, prontamente, se incumbe de promover o ranking das escolas e sistemas de ensino. Fica o compromisso de a escola, de modo particular, realizar a justificação mediante mecanismos que ela mesma implementa seguindo suas condições idiossincráticas. No caso dos municípios, a justificação se dá especialmente pelo mecanismo do PAR, que impõe a adoção, pelos governos, de uma metodologia própria e indutiva.Talvez por falta de tempo ou, ainda, por dificuldade de interpretar o mecanismo de composição do IDEB, especialmente no tocante às notas da Prova Brasil, em algumas situações, escolas aceitam passivamente os resultados e, se chamadas a justificar-se, apresentam argumentos pouco consistentes acerca de uma pontuação considerada indesejável (abaixo da meta projetada para o biênio). Se a pontuação do IDEB for favorável (compatível com a meta projetada), não raras vezes essas mesmas escolas esquecem-se de promover uma reflexão mais ampla sobre o significado real daquela pontuação.

Pelas razões apresentadas, somos levados a concluir que o modelo de accountability subjacente ao IDEB aproxima-se dos pressupostos que conformam as novas formas de gestão dos serviços públicos, bastante disseminadas em outros países ocidentais. Esse modelo carece de um processo que permita emitir juízos valorativos mais consistentes acerca das práticas, instituições, contextos e políticas educacionais em curso no Brasil. Desse modo,

(...) sem congruência de pressupostos, valores e metodologias entre avaliação, prestação de contas e responsabilização torna-se mais difícil haver uma procura de objectividade e transparência relativamente a decisões e práticas políticas, sociais e educacionais, podendo estar em causa a concretização do direito democrático à informação e, em decorrência disso, a possibilidade de afastamento e alheamento dos cidadãos face ao que acontece nas instituições e organizações públicas ou de interesse público (Afonso, 2009a, p. 15).

Em suma, as evidências apontadas são suficientemente indicativas de que o IDEB constitui uma fase inicial de construção de um modelo de accountability em educação no Brasil. No entanto, pouco se pode dizer acerca das possibilidades de avanço deste modelo para a construção de um sistema mais amplo, que incorpore preocupações efetivas com as dimensões éticas, 
de justiça, democracia e participação crítica e ativa, visto sua aproximação com protótipos pautados em perspectivas neotayloristas, nomeadamente as que informam o campo educacional.

\section{Considerações finais}

A despeito de posicionamentos dissonantes acerca da potencialidade do IDEB para os propósitos almejados, a criação de um instrumento de aferição de qualidade da educação básica pode representar um avanço nas condições de acompanhamento e monitoramento da situação educacional formal brasileira. Os dados produzidos e divulgados a cada biênio são potencializadores da produção de políticas e da implementação de ações focadas nas metas de qualidade educacional no país, especialmente em nível de redes de ensino e escolas.

Não obstante, o índice constitui-se a partir de indicadores que visam, predominantemente, o exercício de prestação de contas e de controle por parte do Estado. Serve, por iniciativa do mercado e dos media, como importante ferramenta na produção de rankings das escolas públicas. Por essas razões é que julgamos que a política em que se inscreve o IDEB, nas condições postas, não avança em relação a concepções de accountability que possam ser articuladas com uma política educacional de qualidade. Predomina, no modelo implantado, certa incongruência entre a avaliação que pretende aferir a qualidade da educação básica e a constituição de um sistema amplo, complexo e integrado de avaliação, prestação de contas e responsabilização. Ainda que a avaliação preceda a etapa da responsabilização, ela coloca em causa apenas o desempenho dos estudantes e das escolas, excluindo outros fatores que intervêm nas condições de qualidade.

Um sistema de prestação de contas e de responsabilização, como o que o IDEB procura integrar, não pode prescindir de uma avaliação e de uma autoavaliação referenciadas, congruentes com o postulado de uma educação democrática na qual as políticas educacionais contemporâneas estão subscritas. Para alcançar esse intento, a escolha de estratégias mais participativas, tal qual previsto na Carta Magna, com o estabelecimento de trajetórias ordenadas por parte do Estado e compatíveis com os novos 
cenários em construção no século $\mathrm{XXI}$, parece-nos uma via que ainda está por ser construída.

\section{Notas}

1 Pelo Decreto n. 6.094, de 24 de abril de 2007, o governo brasileiro implementou o Plano de Metas Compromisso Todos pela Educação, pela União Federal, em regime de colaboração com o Distrito Federal, estados e municípios, e a participação das famílias e da comunidade, visando à mobilização pela melhoria da qualidade da educação básica brasileira.

2 Para definir a meta que representaria o parâmetro de qualidade traduzido pelo IDEB, foi efetuada uma compatibilização entre os níveis de desempenho adotados pelo PISA de 2003 e a escala do Saeb de 2003 (Fernandes, 2009). Os resultados obtidos teriam permitido estimar quais seriam os IDEB dos países participantes do PISA (se estes o tivessem) e, a partir disso, definir qual seria a meta desejável para o Brasil.

3 Por ter divulgação bienal, foram disponibilizados à comunidade educacional e à sociedade, em geral, até o momento, resultados do IDEB de 2005, 2007, 2009 e 2011.

4 Apesar de a criação ter ocorrido em 2007, na primeira edição houve uma estimativa de qual teria sido o IDEB de cada escola e município em 2005. Assim, no ano de sua criação foi divulgado o IDEB de 2005 e 2007, simultaneamente.

5 Pollitt (1993) considera o neotaylorismo um modelo particular de gerencialismo, bastante estreito e mecaniscista, semelhante à escola da administração científica do final do século XIX e início do século XX, cujo foco era o controle burocrático. Apesar de construído como um novo gerencialismo, segundo o autor, esse modelo preserva muitos dos pressupostos econômicos e eficientistas daquele que desejava suplantar.

6 Dentre os três pilares, talvez o mais controverso, apesar de mais referenciado, seja exatamente o da responsabilização, redutoramente vinculado à ideia de ameaça ou imputação negativa de culpa. Entre os que defendem a adoção das ferramentas da accountability na educação, há os que reclamam justamente o reforço da responsabilização, de escolas e docentes, pelos resultados educacionais. Para alguns autores, o seu caráter pouco expressivo resulta na implementação de uma "accountability fraca" (Hanushek \& Raymond, 2004).

7 Pela via da Prova Brasil, o modelo de accountability erigido pelo IDEB alcança somente o ensino fundamental tendo em vista que, no ensino médio, a avaliação não atinge censitariamente as escolas públicas. Para esse nível, o Brasil conta com outra avaliação, o Enem (Exame Nacional de Ensino Médio) (Fernandes \& Gremaud, 2009).

8 Para o cálculo de cada uma das etapas $\left(1^{\mathrm{a}}\right.$ a $5^{\mathrm{a}}$ séries, $6^{\mathrm{a}}$ a 9 séries e ensino médio), o tempo T é obtido com base no fluxo escolar dos alunos de todas as séries da etapa correspondente. Assim, interessa o equilíbrio nas taxas de aprovação de todas as séries da etapa avaliada. 
9 Consoante destacam Schneider, Nardi, e Durli (2012, p. 306), o PAR foi criado em 2007 como um programa estratégico do PDE. Por meio dele, o MEC promete apoio técnico ou financeiro aos municípios, estados e ao Distrito Federal, prioritariamente àqueles com baixa pontuação no IDEB. Como um Plano geral e abrangente, cuja efetividade depende das unidades subnacionais e das escolas, "(...) traduz um processo de regulação na medida em que orienta condutas, define as 'regras do jogo' e exerce coordenação e controle, objetivados e institucionalizados em dispositivos materiais, legais e técnicos promovidos pelo Estado" (Schneider et al., 2012, p. 306).

\section{Agradecimento}

Agradecemos ao professor Almerindo Janela Gonçalves Afonso que, com sua leitura cuidadosa, contribuiu para o aprofundamento do tema e o aperfeiçoamento do texto.

\section{Referências}

Abrucio, F. L. (1997). O impacto no modelo gerencial na administração pública: Um breve estudo sobre a experiência internacional recente. Brasília, DF: Enap (Série 10).

Afonso, A. J. (2009a). Nem tudo o que conta em educação é mensurável ou comparável: Crítica à accountability baseada em testes estandardizados e rankings escolares. Revista Lusófona de Educação, 13, 13-29.

Afonso, A. J. (2009b). Políticas avaliativas e accountability em educação: Subsídios para um debate ibero-americano. Sísifo, 9, 57-69.

Afonso, A. J. (2010). Um olhar sociológico em torno da accountability em educação. In M. Esteban \& A. J. Afonso (Org.), Olhares e interfaces: Reflexões críticas sobre a avaliação (pp.147-170). São Paulo: Cortez.

Afonso, A. J. (2012). Para uma conceitualização alternativa de accountability em educação. Educação \& Sociedade, 33(119), 471-484.

Bovens, M. (2007). Analysing and assessing accountability: A conceptual framework. European Law Journal, 13(4), 447-468.

Decreto $\mathrm{n}^{\circ}$ 6.094, de 24 de abril (2007). Diário Oficial [da] República Federativa do Brasil, Poder Executivo. Brasília. Seção 1, 5-6.

Erkkilä, T. (2007). Governance and accountability: A shift in conceptualization. Public Administration Quartely, 31(1/2), 1-38.

Fernandes, R. (2007). Índice de desenvolvimento da educação básica (IDEB). Brasília: Inep.

Fernandes, R. (2009). Índice de desenvolvimento da educação básica (IDEB). In Ações premiadas no $14^{\circ}$ Concurso Inovação na Gestão Pública Federal. 2009 (pp. 6175). Brasília: ENAP. 
Fernandes, R., \& Gremaud, A. (2009). Qualidade da educação: Avaliação, indicadores e metas. 2009. Disponível em: http://www3.fgv.br/ibrecps/rede/seminario/ reynaldo_paper.pdf (acesso em 20 de março de 2012).

Hanushek, E. A., \& Raymond, M. E. (2004). Does school accountability lead to improved student performance? The National Bureau of Economic Research - NBER Working Paper Series (Working Paper No. 10591). Disponível em: http://www.nber.org/papers/w10591 (acesso em 20 de janeiro de 2013).

Ministério da Educação (MEC) (2007). O plano de desenvolvimento da educação: Razões, princípios e programas. Brasília: MEC.

Mulgan, R. (2000). Accountability: An ever-expanding concept? Public Administration, $78(3), 555-573$

Pollitt, C. (1993). Managerialism and the public services. Oxford: UK; Cambridge: USA.

Pollitt, C. (2003). The essential public manager. Open University Press.

Schedler, A. (2004). Que es la rendición de cuentas? Cuadernos de Transparencia 03. IFAI: México.

Schneider, M. P., Nardi, E. L., \& Durli, Z. (2012). O PDE e as metas do PAR para a formação de professores da educação básica. Ensaio, 20(75), 303-324. 
THE IDEB AND BUILDING A MODEL OF ACCOUNTABILITY IN BRAZILIAN BASIC EDUCATION

\begin{abstract}
The objective of this study is analyzing the Indice de Desenvolvimento da Educação Básica (IDEB) - Index of Basic Education Development - as a measure of the Brazilian government to raise the educational performance of students. The analysis takes as reference the concept of educational accountability and seeks to identify which variables that are part of a complete system are more present in the politics defended through IDEB. It also seeks to identify how these variables relate and to what extent the index, which was created in 2007 to assess the quality of Brazilian education, allows going further in comparison to prevailing conceptions of accountability, namely the one that integrates external assessments, account and responsibility as part of a quality educational policy. Based on the tension between the variables that take part in a comprehensive and complex system, it points out IDEB's potentialities considering the conditions of overcoming conservative and reductionist views of educational accountability.
\end{abstract}

Keywords

IDEB; Educational accountability; Brazilian basic education; Education quality

\title{
EL IDEB Y LA CONSTRUCCIÓN DE UN MODELO DE ACCOUNTABILITY EN LA EDUCACIÓN BÁSICA BRASILEÑA
}

\footnotetext{
Resumen

El objetivo del trabajo comprende analizar el Índice de Desarrollo de la Educación Básica (IDEB) en cuanto una medida del gobierno brasileño para evaluar el desempeño educacional de los estudiantes. El análisis toma como referencia el concepto de accountability, tal como propuesto por algunos autores, y procura verificar cuales variables de las que integran un sistema
} 
completo están más presentes en la política defendida a través del IDEB, como ellas se relacionan y en qué medida el índice, creado en 2007 para evaluar la calidad de la educación básica brasileña, permite avanzar con relación a las concepciones predominantes de accountability, nombradamente las que integran evaluaciones externas, prestación de cuentas y responsabilización como elementos de una política educacional de calidad. Con base en el tensor entre las variables que componen un sistema abarcante y complejo, señala potencialidades del IDEB considerando condiciones de superación de visiones reduccionistas y conservadoras de accountability educacional.

Mots-clé

IDEB; Accountability educacional; Educación básica brasileña; Calidad de la educación

Recebido em julho/2013

Aceite para publicação em maio/2014

i Programa de Pós-Graduação em Educação, Universidade do Oeste de Santa Catarina, Brasil

ii Programa de Pós-Graduação em Educação, Universidade do Oeste de Santa Catarina, Brasil

Toda a correspondência relativa a este artigo deve ser enviada para: Marilda Pasqual Schneider, Rua Antonio Pinto, n. 235 - Bairro Alvorada, Videira - SC - Brasil, CEP - 89560-000. E-mail: marilda.schneider@unoesc.edu.br 